\title{
Kathya Araujo
}

\section{La relación con las normas en América Latina y el ordinario trabajo moral del sujeto}

Las ciencias sociales se han interesado desde su nacimiento por el tema de las normas. Ello, por cierto, porque su consolidación como disciplina estuvo inextricablemente ligada a la inquietud moral y política que recorre las sociedades europeas a comienzos del siglo XIX (Nisbet 1973).

Como es posible reconocer, aun cuando no fuera de manera exclusiva, el mainstream de la disciplina se abocó con ahínco a este problema, poniendo el acento en diferentes asuntos: la función de las normas para la integración (Durkheim), la cuestión de la legitimidad de las reglas (Weber, Habermas); el proceso de interiorización normativa (Parsons, Mead); el problema de la desviación y de las sanciones (formales e informales) presentes en todo grupo (Merton, Goffman); la articulación entre el deber moral consciente y las rutinas incorporadas (Bourdieu, Giddens); sin olvidar, por supuesto, la incesante producción de nuevas normas y valores (Joas, Touraine). También se ha constituido en un punto de corte entre autores el peso disímil otorgado a la función que cumplen las normas: a) la de integración social: es decir la función de definir criterios y obligaciones por la cual los individuos son enlazados en un grupo, b) la de orientación: en cuanto definen lo permitido, lo prohibido y en esa medida reducen la complejidad de la elección de metas y medios; o c) la función de coordinación: al permitir la estabilización contrafáctica de las expectativas de acción y con ello asegurar la coordinación de los intercambios entre individuos y subsistemas a largo plazo (Thome 2003).

La presencia de estos debates clásicos en las ciencias sociales en América Latina fue sin embargo relativa, porque el punto de partida fue diferente. No es que se haya desconocido la importancia de la relación con las normas, como lo muestran ya los análisis culturales clásicos. Al contrario, las normas y la relación de los latinoamericanos con las normas han sido una preocupación de base constante en las 
discusiones sobre nuestras sociedades. No obstante, lo que caracteriza a esta discusión es que en el abordaje de esta temática más que de una pregunta se partió de una certeza: nuestra histórica conflictiva relación con la ley. De esta manera, se tomó como premisa que nuestra relación con la ley se caracterizaba por una particular dinámica: una sumisión retórica a esta que no implicaba necesariamente un impacto para nuestras conductas. Al definir esta relación con la ley como rasgo distintivo, ella ha servido para dar cuenta de la cultura, idiosincrasia y funcionamiento de nuestras sociedades. Al mismo tiempo, y por otro lado, como lo discutiremos en detalle más adelante, ha servido de base y fuente para los argumentos a partir de los cuales durante mucho tiempo América Latina, en lo relativo al tema de las normas, ha sido caracterizada a partir de sus deficiencias. El punto de partida adoptado en estas lecturas ha obstaculizado una concepción más rica y compleja de nuestras sociedades y, en la misma medida, ha abonado la retórica del déficit que ha gobernado las lecturas de la región (Araujo 2009a; Martuccelli 2010).

Dicho en breve, si en la discusión europea y estadounidense se puso el acento en el problema de cómo se explica que los individuos sean enlazados al grupo, y se ha partido de la evidencia de la integración para desde allí discutir las posibles desviaciones (Merton), las amenazas a la misma (Durkheim y el concepto de anomia) o, prueba fehaciente del peso de la integración, de sus efectos patógenos (en el modo de la dominación o la sujeción como en el caso de Bourdieu o Foucault); en América Latina el dato de base ha sido precisamente la desviación, la anomia y la desregulación. Lo que constituyó el caso de excepción en otras regiones, fue considerado la media desde la que había que empezar a pensar nuestras sociedades. Y se las pensó en la mayor parte de casos en el modo del déficit y la amenaza, de la condena moral.

Las reflexiones que presentaré en este artículo, al partir del diagnóstico presentado, se nutren de la convicción que requerimos en América Latina de un esfuerzo por ampliar los debates y los estudios empíricos en el ámbito de la sociología de las normas así como por modificar la perspectiva analítica que hemos estado utilizando para abordar a este problema.

Debemos ampliar estos estudios porque la región ha conocido procesos políticos decisivos y contradictorios en las últimas décadas, los 
que obligan a las sociedades civiles latinoamericanas a replantearse de manera profunda sus relaciones con las normas. Ya sea porque las experiencias de violencia política de las últimas décadas empujan a una toma de conciencia colectiva sobre la centralidad del derecho y de los ideales en la producción de una vida civilizada (como en el caso de Chile o el de Argentina, por ejemplo). Ya sea por la aparición de fenómenos inéditos de corrupción, de informalidad, la presencia permanente de actividades ilegales en la vida política y social (tráfico de drogas, etc.) y en muchas ciudades del continente de inquietantes fenómenos de violencia. En cualquier caso, la democracia, pero también la justicia, aparecen ante nosotros, brutalmente, como íntimamente dependientes del funcionamiento de las reglas. La relación con las normas exige ser reconocida como un ítem central para la construcción de sociedades democráticas. Resulta evidente que el éxito de los esfuerzos de democratización de las sociedades no será resultado solamente del desarrollo de estos procesos en clave política, lo será también, siguiendo una intuición temprana de O'Donnell, del grado de "democraticidad" de las relaciones sociales (O’Donnell 1984: 21).

Pero, si la importancia de ampliar los estudios sobre las relaciones con las normas es reforzada por los procesos socio-históricos, no es esta ampliación la única tarea pendiente, como ha sido mencionado. Un argumento central aquí es que se requiere una sociología de las normas que ponga en cuestión la certeza transgresora y deficitaria desde la que ha partido para convertir la relación de los individuos con las normas en una auténtica pregunta de investigación. Es decir, que requerimos de una sociología de las normas que sea exigida a producirse en un marco en el que la comprensión prime sobre la condena moral.

En este artículo me propongo, en primer lugar, un análisis de las maneras en que la premisa del carácter transgresor de la relación con las normas de los latinoamericanos actúa en las producciones contemporáneas sobre el tema así como las consecuencias que tiene una tal pregnancia en nuestros análisis. En segundo lugar, en conversación con lo anterior, presentaré una propuesta de abordaje conceptual para el estudio de la relación con las normas que pone el acento en el rendimiento moral ordinario de los individuos en su relación con estas. Finalmente, presentaré este modelo en obra en el caso de Chile, basándome en resultados de una investigación empírica. 


\section{Los estudios sobre las normas en América latina}

\subsection{Contexto y antecedentes}

Los trabajos que comenzaron a abordar el problema de las normas como un problema fáctico han tendido a desarrollarse muchas veces de manera independiente unos de otros.

Un grupo de estudios se ha centrado en los últimos años en presentar, muchas veces a través de investigaciones empíricas, las cartografías precisas de los actores involucrados en procesos de transgresión, en los mecanismos de la corrupción o en la consolidación de la relación con la justicia (Smulovitz/Urribarri 2007; Schwartzman 2007). Otros, como ciertos trabajos abocados al estudio del sector informal, se interesaron sobre todo en desentrañar las relaciones estructurales de estos fenómenos, poniendo en evidencia, incluso de manera polémica, no tanto las razones de índole propiamente económica, sino los factores que, desde la práctica burocratizada de las reglas, sostienen esta actividad en la región (De Soto 1986). Efectuados desde un abanico sin duda más amplio y complejo de temáticas, y con mayor base empírica que en un pasado aún próximo, estos estudios subrayan sobre todo los efectos perversos o la (in)efectividad de la ley en América latina (Méndez/O’Donnell/Pinheiro 2002).

No obstante, es probablemente el ya clásico y pionero trabajo de Roberto Da Matta (1978), el que abre la vía de manera más clara a los estudios propiamente de las relaciones de los individuos con las normas en las diferentes sociedades nacionales. Tanto el libro de Da Matta como el conocido diálogo que establece con él algunos años más tarde el ensayo de Guillermo O'Donnell (1984), se interesaron en las maneras específicas en que las normas de sociabilidad operaban en distintos contextos nacionales. En estos dos casos, la relación con las normas es discutida en el marco del ejercicio de la autoridad y de los modos en que se estructuran las relaciones de jerarquía en sociedades específicas. El libro de Da Matta, uno de los referentes más importantes en este campo, ofrece un análisis de la sociedad brasilera a partir de diferentes ritos y formas de sociabilidad. El autor discute, de un lado, los ritos integradores en Brasil, entre los cuales destacan las estrategias de expresión controlada de la transgresión, de todos los sectores pero especialmente populares, expresadas plásticamente en el carnaval. Por el otro lado, pone en relieve las formas autoritarias y 
divisionistas de mantener a raya la subversión de las posiciones sociales real o teóricamente diferenciadas, lo que se expresa en la famosa fórmula “¿Usted sabe con quién está hablando?”. Es decir, formas de transgresión de las normas que se apoyan y legitiman por el lugar privilegiado ocupado en las relaciones de poder y jerarquía.

El texto de O'Donnell, defendido como ensayo por el autor pues no se basa en estudios empíricos, se construye en diálogo con el análisis de Da Matta. Comparada con el caso brasilero, la sociedad argentina aparece con mayor "democraticidad" en el trato interclase y en las interacciones sociales, lo que se reflejaría en la pregnancia del tuteo, de la actitud "yo trabajo, no soy sirviente", y en la fórmula que sirve de contrapunto a la del caso de Brasil: "¿Y a mí qué mierda me importa?". No obstante, el autor se guarda de afirmar que se trate de una sociedad democrática o no jerárquica. La fórmula argentina refuerza las jerarquías en la misma medida en que las revela, y al mismo tiempo pone en escena los modos transgresivos y violentos de su enfrentamiento en esta sociedad, bastante lejos de la "cordialidad" brasilera. Ahora bien, el ensayo de O'Donnell consiste propiamente en vincular estas observaciones sobre la sociabilidad con la dimensión más macro, de la política. ${ }^{1}$ En contraposición con este rasgo de la sociabilidad argentina en términos políticos se trata para el autor de una sociedad claramente no democrática. El corporativismo anárquico habría implicado una escena política marcada por la imposición de intereses, en una competencia en la cual el más audaz gana (equivalente a la imagen del tráfico en Buenos Aires, en el que el que "mete la trompa" gana). Una competencia en que toda arma es válida y en la que, por lo tanto, las prácticas transgresivas de las normas (corrupción, desobediencia o uso selectivo de la ley, etc.) son de rigor. A un nivel o a otro, y a pesar de un mayor igualitarismo presente en la sociabilidad argentina, también aquí la lectura subraya el destino transgresivo de la relación con las normas, sea que éste se sostenga como un modo de defensa contra la violencia jerárquica, sea que se presente como efecto de una lógica de intereses desprovista de una ética del bien común.

$1 \mathrm{Y}$ en última instancia con las dictaduras y sus estrategias y políticas represivas, aspecto que dejaremos fuera aquí por no ajustarse a nuestro interés argumentativo. 
Incluso cuando una condena moral era aún implícita en estas posiciones, y el modelo transgresivo opera en estas aproximaciones, ambas tienen el enorme valor de tratar de comprender las formas efectivas de la relación con las reglas presentes en el continente.

\subsection{Los rasgos del campo}

Luego de este debate, el campo de las discusiones sobre la relación de los individuos con las normas en América Latina se ha caracterizado principalmente por dos rasgos: 1) su escaso sustento empírico, 2) compartir un diagnóstico descriptivo común que devela un marco de comprensión compartido.

Primero. A pesar de la potencia explicativa que se le ha adjudicado a esta dimensión, de manera paradójica los estudios empíricos que se han emprendido son extremadamente escasos. El debate se ha dado principalmente a partir de producciones ensayísticas, o sobre lecturas indirectas sostenidas en interpretaciones culturalistas-historicistas (cfr., p.ej., solo para el caso de Chile, Larraín 2001; Garretón 2000; Jocelyn-Holt 1999).

No es posible dar una explicación certera de las razones de esta característica del debate, que por lo demás no se restringe a nuestra región, pero plausiblemente una de las razones es que el abordaje de esta temática requiere acercarse al problema de la moral social, entendida más allá de la mera conjunción de actitudes u opiniones (como, por ejemplo, los acercamientos de tipo cuantitativo vía encuestas de opinión), lo que necesariamente obliga a la producción de perspectivas teórico y metodológicas trans o interdisciplinarias exigentes. Una siguiente razón, se puede vincular con el poco interés por temas ligados al campo de la moral en las ciencias sociales latinoamericanas, especialmente aquellas asociadas con una posición crítica en las últimas cuatro décadas, por lo menos. De un lado, por la convicción de que existían otros temas prioritarios como el desarrollo, la pobreza o la democratización. Del otro, porque la moral apareció considerada como una temática propia al reducto de posiciones conservadoras. El problema de la moral individual y social no consiguió tener el brillo que le permitiera llamar la atención de la investigación social sobre él.

Segundo rasgo del campo, lo diré brevemente porque ya lo he desarrollado: América Latina estaría caracterizada por el carácter tras- 
gresor de los individuos. Es el tono de un texto fundamental en este campo como Carnavales, Malandros y Héroes de Roberto Da Matta, como acabamos de discutirlo, pero también, y a fin de cuentas, sobre sociedades como la chilena, en la cual tras la afirmación del "legalismo" que la caracterizaría se discute la existencia de un permanente "doble discurso" (Shepard 2000). Una relación oblicua con una ley nunca suficientemente eficiente ni legítima es lo que encontramos como piedra de tope en este debate.

Lo que resulta relevante poner en relieve aquí, es que esta interpretación revela la permanencia de un enfoque que pone el acento en la distancia entre las normas y los individuos y sus conductas. Esto se expresa en los diagnósticos culturales, pero también en muchos trabajos que ponen el acento explicativo en la distancia entre prácticas y discursos o representaciones. El problema aquí es que una vez que hemos definido la distancia con la norma, no sabemos exactamente aún qué significa ello en la economía societal e individual. No es posible determinar sin un forzamiento, por ejemplo, si eso que llamo trasgresión en el análisis, es concebido como trasgresor y si tiene un efecto de erosión o no en la sociedad. En contraposición, las lecturas de la transgresión han estado moduladas por un implícito juicio moral o de valor.

\subsection{Claves interpretativas y sus trampas}

La distancia entre los individuos y la norma ha sido interpretada en por lo menos dos grandes claves. En primer lugar, el desajuste entre normas y conductas es considerado principalmente como una amenaza contra las sociedades. Un ejemplo paradigmático en este sentido es el trabajo de Carlos Santiago Nino, para el caso de Argentina (Nino 1992). Nino ha propuesto que lo que caracteriza a esta sociedad es la presencia de lo que denomina una "anomia boba", la que entiende como un estado de inobservancia de normas ya sean jurídicas, sociales o morales que son en todo contraproducentes para la sociedad. Las dificultades en el desarrollo y bienestar argentino estarían correlacionadas con este rasgo constitutivo de la relación con las normas en el país.

Una segunda manera en que la distancia entre conducta individual y norma es interpretada es aquella que entiende que los desajustes no 
solo resultan inevitables sino también positivos. El ejemplo de los trabajos de Nugent $(1996 ; 1998 ; 2003)$ es expresivo en este sentido, pero también una parte de las discusiones de los estudios feministas sobre las transformaciones de género y el valor de la puesta en cuestión normativa. Para Nugent, en el caso peruano la trasgresión debe ser vista como resultado de acomodos y resistencias a relaciones de poder en una sociedad jerárquica y en el contexto del empuje modernizador-modernizante. La inobservancia de las normas es una respuesta activa y positiva de los subordinados en el reacomodo necesario en una sociedad en la que ciertos sectores pierden rápidamente las bases materiales y simbólicas de la legitimidad que había sostenido su poder. La transgresión en el Perú contemporáneo, sería así, una modalidad de resistencia a la jerarquía pero también de agencia modernizante social.

Si bien los estudios que se ubican tanto en una clave de lectura como en la otra han aportado al debate sobre las reglas en nuestra región, lo cierto es que es posible perfilar dos grandes trampas potenciales que se derivan de cada una de estas claves de lectura.

En la trampa normativista los análisis se abocan a definir la distancia entre ideal y actuación del individuo. De esta manera, la pregunta que subyace a estos abordajes es por las razones que explican que los individuos no actúen según los ideales que dicen tener. Formulada de este modo, la noción de déficit juega un papel central y una cierta perplejidad e impotencia acompañan las interpretaciones. Esta perplejidad y lo que es percibido como un aparente muro para el análisis es efecto en buena medida de la suposición de base de estas posiciones: la existencia de una relación inmediata entre las reglas y los individuos. Dicho de otro modo, lo que está en juego es la convicción de que existiría una relación directa entre los ideales y las conductas. La concepción moral es formal y abstracta. Lo que con en este modelo es puesto en exclusión es la actuación de la experiencia social. Obvia que esta es materia prima para el trabajo moral y en consecuencia la extrae del campo de análisis. Esta trampa normativista conduce a que la "insuficiencia" o "inferioridad moral" de latinoamericanos y latinoamericanas resulte de entrada una conclusión.

La trampa pragmativista, por su parte, se vincula con la suposición de una preeminencia de las determinaciones sociales por sobre el individuo. Las conductas de estos son concebidas como resultado del em- 
puje de la estructura económica o de las relaciones sociales, ya sea como acatamiento, ya sea como reacción refleja a ellas. Lo que subyace es la concepción de que existiría una articulación inmediata entre la experiencia social y el sujeto. La experiencia social aparece aquí como el todo explicativo suficiente de la relación con la norma que establecen los individuos y, en muchos casos, es fundamento de la disculpa moral basada en la denuncia social. Así, por ejemplo, una cierta lógica argumentativa de estas posiciones propone que es porque la experiencia social está armada a partir de abusos permanentes que el recurso al ideal sería una actitud imposible. Lo que se excluye o no se considera adecuadamente aquí es la función del ideal en la orientación de las conductas. Como efecto de la exclusión del Ideal, se obvia toda configuración de sujeto moral positiva y ordinaria en los individuos.

Como es visible, en ambas trampas el juicio moral texturiza el análisis social. El juicio moral que recae sobre el individuo en el caso de la trampa normativista. El que recae sobre la sociedad, en el de la pragmativista. En los dos casos una elisión doble se evidencia: del lado del primero, la elisión de la experiencia social; del lado del segundo, la elisión de la función del ideal. En ambos, y esto es un argumento central en este texto, lo que se revela es la omisión del activo y ordinario trabajo moral de los individuos.

Tanto las respuestas que ponen el acento en los efectos modeladores de las normas como aquellas que privilegian una perspectiva más pragmática transportan el presupuesto que los individuos actúan y se orientan sin mediación alguna de su propio trabajo y principalmente moral.

\subsection{Pensar las salidas}

Hecho el breve estado del arte anterior, ¿cómo enfrentar, entonces, el estudio de las relaciones de los individuos con las normas? A nuestro juicio son tres las direcciones centrales que se requiere tomar:

1) Evitar una estructura analítica que se centre en la distancia de los individuos respecto a la norma, la que conduce necesariamente al diagnóstico común de la trasgresión. Por el contrario se trata de atender a los procesos que impactan en los individuos y que producen y sustentan sus formas de relación a las normas y las formas en que éstos responden a ello. La propuesta aquí es poner la aten- 
ción no ya a la distancia de los individuos con la norma sino a la lógica de su relación con ella.

2) Superar la omisión del trabajo de los individuos por producirse como sujetos y sujetos morales. Ello implica integrar al análisis el hecho que la acción individual por más banal o insignificante que sea está orientada por una modalidad de sujeto, un sujeto que funciona como orientación y legitimación de la acción.

3) Complejizar los marcos conceptuales para evitar elisiones que empobrecen y mecanicen los análisis. Resulta indispensable, en este sentido, reconocer conjuntamente la función combinada del Ideal y de la experiencia social.

En breve, respetar la especificidad de la relación de los individuos con la norma implica la creación de un abordaje teórico y conceptual que garantice la aprehensión de la pluralidad de lógicas, marcos y estrategias que componen esta relación. Para decirlo de la manera más precisa posible: el estudio de los individuos en su relación con la norma implica dar cuenta de las lógicas y estrategias a partir de las cuales se orientan y conducen en lo social (si cruzan un semáforo rojo, si rechazan una oferta de corrupción, si movilizan recursos de influencia fuera de la ley, etc.). Dicho de otro modo, aún, cuando alguien pasa por delante de decenas de personas gracias a sus influencias, ello no puede ser entendido como simple ceguera o definido cinismo. Es indispensable dar un paso más. Resulta necesario responder de qué manera una acción tal es integrada por los individuos de una sociedad en la comprensión de sus actos y de dónde extraen su legitimación (o no). En otras palabras, de qué modos y a partir de qué nociones de si y del mundo es posible encadenar el acto de pasar por encima de los derechos de las otras personas a la serie de las acciones o trayectorias individuales. Responder por las modalidades en que los individuos se relacionan con las normas supone integrar la dimensión moral de los actos ordinarios al horizonte de los individuos comunes.

A nuestro juicio, una inteligencia de la acción social que responda a estos requisitos pasará por introducir en nuestro horizonte analítico y de manera simultánea a los ideales y las experiencias sociales propias a una sociedad, pero restituyendo en toda su magnitud el lugar debido al ordinario trabajo moral del sujeto. 


\section{El ordinario trabajo moral: las configuraciones de sujeto}

Los procederes individuales no pueden ser entendidos como respondiendo aisladamente a uno $\mathrm{u}$ otro, a ideal o a experiencia, pero tampoco como una combinación mecánica de ambos elementos. Para evitar una explicación mecanicista se requiere incorporar un tercer término que dé cuenta de la función y el precipitado de la articulación de ambas dimensiones. Este tercer término es el sujeto.

Son las configuraciones de sujeto, las que son fuentes de orientación y legitimación de las acciones individuales y, por lo tanto, están en el lugar de dar cuenta de la inteligencia de los modos de actuación en lo social. Pero ¿cómo entender la configuración de sujeto? Es la tensión entre experiencias sociales e ideales, la que va a participar en la definición de las opciones y modalidades de configuración de sujeto posibles en una sociedad. Pongamos un ejemplo: los principios meritocráticos. Si mi experiencia, ya sea producida por lo vivido directamente o por lo que me ha sido relatado, me dice que las relaciones personales, y las influencias que de ello derivan, tienen un peso significativo en los procesos de selección de personal y contratación, aunque el ideal de sujeto moderno cuyo valor reside en sus méritos individuales pueda estar funcionando como ideal movilizador para mí, me puedo ver inclinado a actuar en función de lo que la primera me muestra. El saber decantado de lo social muestra que mi valor reside en el entramado de relaciones familiares y amicales al que pertenezco y que puedo movilizar. El sujeto que puedo ser se define entonces en este interregno que es constituido por los ideales que me orientan y lo que mi experiencia social me dice sobre las vías posibles, aconsejables y eficientes para presentarme y conducirme en lo social. Por supuesto, las posibilidades de configuración de sujetos son plurales en una sociedad. No hay una sola manera en que esta configuración se defina. Volveremos sobre el punto más adelante cuando presentemos un caso empírico.

Ahora bien, el sujeto no es un producto acabado y permanente. Es el trabajo constante de su configuración, reconocible en los momentos de su actualización. El sujeto es el resultado de un trabajo permanentemente inacabado de conformación en el marco de las expectativas, restricciones y posibilidades sociales. Así, una configuración de sujeto es un producto siempre inconcluso y es, simultáneamente, el trabajo 
mismo de su permanente creación (Araujo 2009a). Un trabajo que se desarrolla en el marco de los desafíos que se presentan de cara a los ideales que funcionan como orientación y del saber decantado de las experiencias sociales.

Es la acción combinada de las experiencias sociales en su encuentro con los horizontes producidos por el Ideal, lo que va a definir las posibilidades y modalidades de cada cual para configurarse como sujeto: el que define las vías abiertas y vedadas, las estrategias apropiadas e inapropiadas para presentarse y habitar lo social. Por otro lado, esta dualidad explica, por un lado, su carácter provisorio -porque siempre estoy obligado por las experiencias sociales a producir y reproducir el trabajo de mi configuración en cuanto sujeto. Por otro lado, permite dar cuenta del "aire de familia" conservado a lo largo del tiempo -en la medida en que los ideales inscritos en el Ideal del Yo individual procuran una relativa estabilidad.

La noción de configuración de sujeto permite así incorporar la dimensión subjetiva pero lejos de una concepción intimista o afectiva (p.ej., Lechner 2002; PNUD 1998), o como mero exceso fantasmático (Žižek 1992; 2001). Al mismo tiempo habilita a incorporar al sujeto sin caer en el modelo que hace de él una figura producto de un entramado puramente discursivo (Foucault 1990; 1998). El sujeto es la actualización que se deduce de un trayecto o un curso de acción, cuyas condiciones de posibilidad están definidas por la acción compleja y combinada de los ideales y de las experiencias sociales.

En este marco interpretativo, es indispensable comprender de manera precisa el rol del ideal. El Ideal no es referencia única, aunque su acción es constante. Por otro lado, y de manera central, el sujeto ideal no es el sujeto encarnado. Primero, porque los ideales sociales no actúan de manera directa y mecánica influyendo los procederes de los individuos (como lo supuso en el fondo el modelo clásico de la socialización), sino que encuentran su camino por un proceso de inscripción individual vía Ideal del Yo. Segundo, porque el sujeto no precede a la experiencia. El sujeto se produce en relación con la experiencia y en cierta medida como su efecto. Suponer que hay un sujeto ideal más allá de la experiencia social, del cual se espera que cumpla con sostener la norma, es, por decir lo menos, un exceso de idealismo en la concepción de sujeto, el que nos conduce a callejones sin salida cuando intentamos dar cuenta de los fenómenos que enfrentamos. 
Las configuraciones de sujeto no son meramente normativas, en el sentido que, aunque funcionan como orientación y soporte, no están constituidas puramente por una dimensión ideal. Una visión que, como lo muestra el célebre trabajo de Robert Bellah y su equipo, conduce a privilegiar un número reducido de modelos de sujeto, fuertemente normativos, que los individuos se limitarían a encarnar en proporciones variables (Bellah et al. 1985). De esta manera, el individuo no está librado a la acción del ideal. Dicho en otros términos, no está en posición de indefensión pasiva o acatamiento necesario frente a la dimensión normativa. Los ideales, los modelos de sujeto y los dispositivos que buscan encarnarlos materialmente no se apropian totalmente de las conciencias y de los cuerpos, porque la experiencia social funciona como barrera y como tope. Visto desde la perspectiva del lazo social y la convivencia social: los ideales en una sociedad son intrínsecamente inestables y frágiles porque estarán siempre a merced de los impactos y requerimientos que emergen de la experiencia social.

Es esta articulación permanente que da cuenta de la maleabilidad de las configuraciones de sujeto, como hemos sostenido, pero también de la imposibilidad de considerar experiencia social e ideal normativo fuera de los efectos de su interacción capturada por el trabajo de su articulación.

Intentemos ahora mostrar en obra esta propuesta en el caso de la relación de los individuos con las normas en la sociedad chilena.

\section{El caso de los sectores medios en Chile}

La investigación desarrollada para el caso de Chile partió de la pregunta por la manera en que el derecho en cuanto ideal normativo participaba o no en la regulación de las relaciones cotidianas entre las personas y entre éstas y las instituciones. Se interrogó así por el conjunto de elementos a partir de los cuales las acciones de los individuos resultaban inteligibles así como cuáles eran las formas de justificación y legitimación para el tipo de relación con las normas que ellos establecían. ${ }^{2}$ En lo que sigue me detendré a dar un ejemplo preciso de la

2 Con la orientación de esta pregunta se aplicó la técnica de Grupos de Conversación Dramatización a hombres y mujeres de generaciones y dos sectores socioeconómicos distintos. Esta investigación fue posible gracias al apoyo de Oxfam Gran Bretaña. Mi agradecimiento a Carolina Ibarra, Claudia Moreno, y María 
manera en que los avatares del ideal y las características de la experiencia social se articulan en determinadas configuraciones de sujeto. La explicación de la relación de los individuos con las normas se nutre de los destinos de la inscripción del ideal, de la reconstrucción del paisaje y las lógicas sociales a partir de las experiencias de los individuos para arribar a ciertos modelos de sujeto que testifican de los tipos de relación con la norma más frecuentes en una sociedad. Tomemos el caso de los sectores medios chilenos.

\subsection{El Ideal}

En estos sectores se aprecia la enorme difusión y extensión en el uso de la noción de derecho en los modos en que se constituyen las expectativas sobre lo social pero también de sí en él. Esta noción aparece como una herramienta a partir de la cual los individuos codifican y producen significaciones en los diferentes ámbitos de la experiencia social. Aún ámbitos que no están sometidos a la regulación por los derechos positivos, como por ejemplo las normas de cortesía, aparecen siendo concebidas como campos regulados por la lógica del derecho. De esta manera, los "derechos" percibidos y su campo de acción exceden en mucho lo que es efectivamente cubierto por los mismos en su vertiente positiva. Junto a los derechos laborales se apela al derecho a ser bien tratado, a que no se le deje esperar o a que otra persona lo escuche. La casi totalidad de los intercambios y las relaciones con otros es codificada haciendo uso de esta noción, estableciendo una modalidad hegemónica, y monocorde, de apelar a los principios plurales de justicia. En breve: el derecho como ideal tiene un lugar definitivo en las expectativas sobre el funcionamiento de lo social y una función clara como orientación ideal en las configuraciones de sujeto.

\subsection{Las experiencias sociales}

No obstante, esta extensión e inscripción del ideal normativo se acompaña paradójicamente con la lectura de su experiencia social como un campo de masiva vulneración de los mismos y, más específicamente, de una vulneración normalizada. La experiencia de vulnera-

Elena Fuentes por su aporte en la realización de la investigación. Una presentación y discusión detallada de la técnica de investigación y de los resultados se puede encontrar en Araujo (2009b). 
ción aparece como parte consustancial del paisaje social y de la experiencia cotidiana. La magnitud de la percepción de vulneración, es decir su masividad y su "normalización" responde, por lo menos parcialmente, a la contradicción entre un muy robusto ideal normativo del que hacen uso los sujetos, y una realidad social que contradice los principios sobre los que este orden debería fundarse.

Lo que su experiencia social les muestra es que son principalmente dos lógicas que ponen en cuestión el orden de derecho y lo que es reconocido como su fundamento por estos sectores: el principio de igualdad. Por un lado, la lógica del privilegio. Por el otro, la lógica de la confrontación de poderes. La percepción de la extensión de recursos de poder que no corresponden al marco de derecho pero que se movilizan y actualizan en campos de relaciones que se suponen reguladas por éste, apoya la deslegitimación de una visión de la vida social como un orden regido por el ideal normativo. Se trata aquí, entonces, de un ideal que ordena la lectura de lo social y que funciona como elemento estructurante de la noción de sujeto misma, por un lado, pero que en el encuentro con la masividad de las experiencias sociales que lo ponen en cuestión no alcanza para orientar los actos e interacciones. $\mathrm{Su}$ falta de legitimidad y poder en las interacciones sociales concretas hace que sean otras las estrategias a las que los individuos apelan. Aunque se lea la situación en términos de derecho ("está vulnerando mi derecho"), se actúa sobre la base de lógicas efectivas distintas (se hace uso del tráfico de influencias o se produce una posición de "sometimiento estratégico" a las arbitrariedades del otro, por ejemplo).

La experiencia social así definida conduce a la entronización de la dinámica ventaja-desventaja. Ella revela la amenaza que constituye para cada cual encontrarse en desventaja, al mismo tiempo que impregna del sentimiento de encontrarse en riesgo de caer en esta situación. La experiencia social muestra, de este modo, que la condición de base para configurarse y sostenerse como sujeto es poder manejar o resguardarse lo mejor posible de los efectos de las lógicas del privilegio y del poder. La paradoja está, por tanto, en el reconocimiento que para sostenerse como sujetos en lo social resulta absolutamente necesario participar en las lógicas sociales que ellos mismos denuncian como atentatorias contra lo que preservan a pesar de todo como ideal. 
¿Cómo, entonces, en este contexto de relación entre ideal y experiencia social se constituyen las posibilidades de configuración de sujeto?

\subsection{Las configuraciones de sujeto}

En función de su pregnancia subrayaremos cuatro principales:

1. La primera modalidad de configuración de sujeto es, como puede suponerse, la figura del pragmático. El pragmático se orienta de manera privilegiada a partir de lo que la experiencia social le muestra como las vías indicadas para habitar lo social. En ambos casos, su actuación está sometida a las indicaciones que provienen de la experiencia social. Pero esta configuración de sujeto pragmática se caracteriza por el hecho que, dada la presencia extendida del ideal, junto al peso otorgado a lo que la experiencia social entrega respecto a los resquicios transitables que hay que instrumentalizar y manejar, convive la crítica más ácida a la sociedad y su funcionamiento. Pragmatismo y denuncia se articulan en una lógica particular. Los intereses propios son reconocidos como motor de la acción pero tamizados por la denuncia. En esta modalidad, se trata de "hacer lo que hay que hacer", pero movilizando al mismo tiempo un discurso ideal y edificante de sí. Se está obligado a hacer lo que se está haciendo, porque no hay salida y es parte de la propia lógica de dominación del "sistema", del que no es posible sustraerse. Se "hace lo que hay que hacer", pero se testimonia, retóricamente, de la insatisfacción, se lo relata en términos de forzamiento. Veámoslo ejemplificado en el siguiente diálogo:

Hombre 2: Si mal no recuerdo en [...] una reunión en mandos medios en la famosa ciudad empresarial que está en Huechuraba. Fueron supervisores, mandos medios. Y los gerentes allá arriba contaron maravillas de la empresa, de su seguridad, de todo, todo positivo, todo bonito. Cada área, los jefes, los supervisores, los subgerentes, tenían que exponer con respecto a lo mismo. Y un supervisor se paró con el micrófono y empezó "si en realidad nosotros tenemos estas metas, tenemos todas estas cosas, pero nosotros para poder llegar a estas metas necesitamos, punto uno: capacitación, punto dos, más sueldos, punto tres". Sabes que terminó el tipo, los gerentes estaban así, se veían así como... Pero terminó el tipo la disertación, todos, todos, todos nos paramos en las sillas y empezamos a aplaudir fuerte, aplaudimos con el alma. A la semana siguiente mi compadre, chao.

Mujer 2: No ganaron ninguna...

Mujer 1: Por ser justo... 
Hombre 2: Y ahí tenías un [...] masivo, o sea, habían subgerentes, habían de todos, pero lo que más aplaudieron fueron los jefes hacia abajo. Pero los subgerentes, gerentes...

Mujer 2: Y espérate que si este tipo quiere buscar de nuevo trabajo, ya está $[\ldots]$.

La retórica argumentativa que desculpabiliza al sujeto y apoya el mantenimiento de una imagen de sí valorada, es un rendimiento central que debe ejercer el pragmático debido a la vigencia de la función del ideal. La desculpabilización se apoya en que esta es una estrategia que es percibida como colectiva, o más bien, y de manera más precisa, masiva. Son, lo que puede llamarse, a pesar del contrasentido a primera vista, pragmáticos-idealistas. O sea trágicos. Se inclinan ante la realidad, pero sin perder el horizonte del ideal desde el cual quisieran poder sostenerse. La configuración de pragmático-idealista es una solución resultado de la fuerza de la experiencia social que debe convivir con un ideal extendido y sólidamente sostenido.

2. La segunda modalidad de configuración de sujeto es la que podríamos llamar la del sujeto crítico. En este caso, lo que aparece como predominante es el juicio crítico respecto a la experiencia social, en muchas ocasiones con un alto nivel de elaboración. Se denuncia profusamente la falta de funcionamiento del ideal normativo. Se es capaz de expresar de manera muy detallada las formas consideradas negativas de la relación con la norma que aportan a la erosión del ideal en la sociedad. Se invoca al ideal de derecho como ordenador de las relaciones y se tiene una alta conciencia de la propia condición de sujeto de derecho como un elemento vertebrador de la lectura de sí. La configuración de sujeto crítico es una modalidad que se presenta en dos versiones. La primera que está más claramente vinculada con una posición crítica orientada hacia lo externo. La segunda, lo que podríamos llamar la versión autocrítica.

En la versión crítica que se centra en elementos exógenos, la crítica y la denuncia se produce como un rechazo a lo que en la experiencia social se revela a sus ojos como causa de la erosión del ideal normativo de derecho. Pero los modos de referir son poco discriminadores y más bien se identifica las causas o responsables en entes generalizados o abstractos: "el sistema", "la justicia" o los "poderosos". El ideal normativo es fuertemente sostenido en su calidad de aspiración, 
y la experiencia social claramente rechazada. Pero es la tendencia a colocar la experiencia social como resultado de factores externos de manera tan acentuada, que termina incidiendo en una cierta desresponsabilización.

En la versión autocrítica, el ideal normativo es marcadamente activo. Es una aspiración y una orientación efectiva para el sujeto. No obstante, y esto es tan relevante que regresaremos sobre ello, otros registros son invocados en la lectura de lo que aporta a regular las relaciones sociales - como la cordialidad, la empatía, la humanidad. En este sentido, el ideal normativo de derecho pierde en algo el carácter de instrumento hermenéutico omnímodo que lo caracteriza en estos sectores. En todo caso, esta es una versión que, a diferencia notoria de la versión precedente, pone el acento fuertemente en el acto individual. El sujeto que se configura, es aquel que cuestiona la propia participación en el "desorden del mundo". Se encuentra como efecto de lo anterior una incorporación constante de la responsabilidad propia y una apelación al peso que le corresponde a la acción individual. Puesto que la relación con la norma es percibida como un asunto individual, el campo privilegiado de construcción de la experiencia social es la vida cotidiana. En este sentido, se trata de una modalidad de configuración de sujeto perfiladamente ética, en la que la vigilancia de los propios actos es continuada.

La configuración del sujeto-critico es, así, dual. Las aguas se parten según los cauces de la acción. El primero, el sujeto crítico exógeno es, y se contenta en ser, un comentador y un juez certero del mundo. La lucidez crítica no se traduce en deseo de acción. El segundo, por el contrario el sujeto auto-crítico, es un actor lúcido del mundo. Dicho en pocas palabras: en el sujeto crítico exógeno la crítica socava la acción; en el sujeto autocrítico la conciencia de la urgencia de la acción individual prima sobre la crítica.

3. La tercera modalidad de configuración de sujeto es la orientada por la amargura. Lo que es el pivote aquí es la evidencia de la distancia al Ideal. La amargura sobreviene en la medida en que se hace presente la constatación que ni las "cosas" ni el propio sujeto es lo que podría o debería llegar a ser. Se produce en el intersticio entre ideal y su denegación por la experiencia social. Es la amargura que resulta de la promesa incumplida. 
En la amargura la rabia es todavía un pequeño motor, un surtidor de algo del orden de la pasión que evita la desesperanza y la apatía. En la amargura resta todavía espacio para la denuncia del engaño, para la figura, aunque debilitada, del franco tirador. El pragmático, en el fondo, y a pesar del halo trágico del que hace gala (y del que sabe hacer gala), se ha acomodado con el orden del mundo. Obtiene ventajas de él, evita otras tantas desventajas. El amargado o no puede o no quiere. La brecha entre el ideal y la experiencia en la cual se inscribe el pragmático, se transforma para él en una distancia insalvable. Pero, como el pragmático-idealista y a diferencia de lo que ocurre en los sectores populares, él tampoco renuncia al horizonte del derecho como ideal regulatorio de las relaciones sociales.

El punto mismo de la distancia al Ideal, funciona aquí, entonces, como la escena en la que se fija la mirada. Aquí, como en todas las modalidades de configuración de sujeto encontradas para este sector, el ideal es sostenido y la experiencia social es considerada negativa, pero a diferencia de las anteriores, la experiencia social se impone en su potencia negativa, pero aunque muestra su potencia corrosiva, el ideal se mantiene.

El amargado es prisionero de un dilema al punto que tiende constantemente a deslizarse hacia las dos configuraciones precedentes. $\mathrm{O}$ se esfuerza en darle un contenido más colectivo a su frustración, transfiriendo al "sistema" la brecha insalvable que él resiente entre lo que su ideal le dicta y la experiencia le enseña, y se aproxima por ende al sujeto crítico exógeno. O se esfuerza en imitar lo que hacen los otros, en aprender de ellos, con el objeto de escaparse de lo que ha terminado por convencerse que no es sino el fruto de un conjunto de discapacidades momentáneas y que debe por ende aprender a superar, con lo cual se aproxima al sujeto pragmático. El amargado se configura entre estos dos horizontes. Él vive en un país donde no se aplican las normas, en la medida en que el ideal lo dictaría. Él no puede hacer algo con eso, ni aprovechar los resquicios, ni exteriorizarlo, ni encontrar espacio para la agencia. La amargura lo invade. Frente al país o frente a sí mismo.

4. La cuarta modalidad de configuración de sujeto es probablemente la más problemática. Por un lado, por sus efectos en lo social. Por otro, por la dificultad para cernirla y capturarla analíticamente en el 
modo de la primera persona. Esta es una modalidad extremadamente presente, pero, al mismo tiempo, siempre colocada en tercera persona. Lo que caracteriza esta modalidad es que en nombre de la ley o del derecho, lo que el sujeto encarna es su exceso.

Es la modalidad del sujeto del exceso, un exceso que se materializa en abuso. Es una modalidad en la que se erosiona el ideal normativo amparado en las atribuciones de la autoridad y aún más, en no pocas ocasiones, en nombre del resguardo del propio ideal. Está fuertemente vinculada a instituciones, funciones: a la idea de un colectivo aunque se encarne en alguien singular. Es, en este sentido, que esta modalidad puede proponerse contenida en una afirmación que sería algo así como - "La ley somos nosotros". Se trata del nosotros del colectivo al que se representa -nosotros los médicos, nosotros los ricos, nosotros los padres de familia, nosotros Carabineros, y una lista extensa de otros nosotros-, y que legitima encarnar la ley o la norma que, a fin de cuentas, se erosiona.

Vale la pena reiterar que en el caso de los sectores medios chilenos, el sujeto del exceso, aquel que erosiona la norma, lo hace en nombre del propio orden normativo. Aparece, entonces, como un exceso normativo. El recurso al Ideal aquí se mantiene: se parte apelando a él desde una posición de legitimidad, institucional o social, y se hace uso de esta legitimidad y en nombre de ella, y por cuenta del exceso, se transgrede la norma. Se trata del uso desmedido de la posición de ventaja. Es la traición al Ideal que se trasviste de fidelidad al mismo.

Esta posición orientada por el uso excesivo de la norma, se revela en las actuaciones de aquellos que se sienten en posición de exigir porque pagan:

En el colegio no hay respeto por los profesores, los profesores somos unos empleados, somos nanas prácticamente, los papás porque están pagando ponte tú, ellos son dueños de echarte un par de garabatos (Mujer, mixto, adulto).

También aparece en los atropellos de las fuerzas policiales, como en el caso de un joven al que detienen por consumo de alcohol sin que lo hubiera consumido, en una constelación en la que lo que se pone en juego y se castiga es más bien no haberse comportado con la debida sumisión a la autoridad. Para dar solo dos ejemplos. 
En todos estos casos, las normas se ponen al servicio de los propios intereses o beneficios. El exceso es el sostén mismo del sujeto. El riesgo: que en un contexto marcado por la confrontación de poderes y la movilidad de los lugares ocupados en la dinámica ventaja-desventaja, ésta es una posición siempre provisoria. La exigencia: ella solo sobrevive a condición del éxito de la careta de resguardo con el ideal normativo que le otorga su legitimación: tal es la fuerza de la acción del Ideal normativo en estos sectores.

Las cuatro modalidades son por cierto modelos presentes en la sociedad chilena. No corresponden a perfiles psicológicos individuales: se trata de modos societales de configuraciones de sujeto que dan cuenta de la orientación y legitimación de la acción en un determinado contexto histórico. En este sentido, los individuos encarnados pueden mostrar una mayor pregnancia de un modelo u otro, pero también, pueden en ocasiones transitar entre configuraciones según la coyuntura o incluso el momento vital.

Como lo muestra lo hasta aquí desarrollado, a pesar de que las experiencias sociales y la inscripción del ideal puedan tener características compartidas para un sector social (o para un género o una generación), ellos no remiten de manera mecánica a la misma relación con las normas. Es una determinada articulación de las mismas la que constituirá el entramado de las diversas configuraciones de sujeto posibles en una determinada sociedad. Aunque las experiencias sean similares, y los ideales inscritos del mismo tenor, siempre queda el espacio de libertad, esto es la exigencia ética, que se abre para cada cual para definir sus relaciones con el mundo, con los otros y consigo mismo.

Decir que los sectores medios chilenos son trasgresores sería tan falso como sostener lo contrario, y, en todo caso, no conduce demasiado lejos. Lo importante es poner en relieve de qué manera en esta sociedad el desafío principal al que deben enfrentarse es a la relación entre un ideal de desplegada presencia y una realidad social que se encarga de manera constante de desmentirlo. Es en este interregno que el ordinario trabajo moral del sujeto, como venimos de verlo, es capaz de dar cuenta de las variantes en la relación que establecen los individuos con las normas en una misma sociedad sin, al mismo tiempo, pluralizar indefinidamente el análisis al reducirlo a variantes psicológicas individuales. 


\section{Bibliografía}

Araujo, Kathya (2009a): Dignos de su arte. Sujeto y lazo social en el Perú de las primeras décadas del siglo XX. Madrid/Frankfurt am Main: Iberoamericana/Vervuert.

- (2009b): Habitar lo social. Usos y abusos en la vida cotidiana en el Chile actual. Santiago de Chile: LOM.

Bellah, Robert N./Madsen, Richard/Sullivan, William M./Swidler, Ann/Tipton, Steven M. (1985): Habits of the Herat. Berkeley: University of California Press.

Da Matta, Roberto (1978): Carnavales, malandros y héroes. Hacia una sociología del dilema brasileño. México, D.F.: Fondo de Cultura Económica.

De Soto, Hernando (1986): El otro sendero. Lima: El Barranco.

Foucault, Michel (1990): La arqueología del saber. México, D.F.: Siglo XXI.

- (1998): Las palabras y las cosas. Una arqueología de las ciencias humanas. Madrid: Siglo XXI.

Garretón, Manuel A. (2000): La sociedad en que vivi(re)mos. Santiago de Chile: LOM.

Jocelyn-Holt, Alfredo (1999): El peso de la noche: nuestra frágil fortaleza histórica. Santiago de Chile: Planeta.

Larraín, Jorge (2001): Identidad chilena. Santiago de Chile: LOM.

Lechner, Norbert (2002): Las sombras del mañana. La dimensión subjetiva de la politica. Santiago de Chile: LOM.

Martuccelli, Danilo (2010): ¿Existen Individuos en el Sur? Santiago de Chile: LOM.

Méndez, Juan E./O'Donnell, Guillermo A./Pinheiro, Paulo S. (comps.) (2002): La (in)efectividad de la ley y la exclusión en América Latina. Buenos Aires: Paidós.

Nino, Carlos Santiago (1992): Un país al margen de la ley: estudio de la anomia como componente del subdesarrollo argentino. Buenos Aires: Emecé.

Nisbet, Robert A. ([1966] 1973): The Sociological Tradition. London: Heinemann Educational Books.

Nugent, Guillermo (1996): El poder delgado: fusiones, lejanías y cercanías en el diseño cultural peruano. Lima: Friedrich-Ebert-Stiftung.

- (1998): Composición sin título: sobre democracia y diversidad cultural en el Perú. Lima: Friedrich-Ebert-Stiftung.

- (2003): "Clase media: de la mano invisible a la clase invisible". En: Perú hoy. No. 4: La clase media ¿existe? Lima: Desco, pp. 15-46.

O’Donnell, Guillermo A. (1984): ¿Y a mi qué me importa? Notas sobre sociabilidad y política en Argentina y Brasil. Buenos Aires: CEDES.

PNUD (Programa de las Naciones Unidas para el Desarrollo) (1998): Informe Desarrollo Humano en Chile. Las paradojas de la modernización. Santiago de Chile: PNUD.

Schwartzman, Simon (2007): Coesão social, democracia e corrupção. São Paolo: IFHC. 
Shepard, Bonnie (2000): "El Doble Discurso sobre los Derechos Sexuales y Reproductivos en América Latina: el Abismo entre las Políticas Públicas y los Actos Privados". En: Revista Conciencia Latinoamericana, $\mathrm{N}^{\circ}$ 3. Córdoba: Católicas por el Derecho a Decidir.

Smulovitz, Catalina/Urribarri, Daniela (2007): Poderes judiciales en América latina: entre la administración de aspiraciones y la administración del derecho. São Paulo: IFHC.

Thome, Helmut (2003): "Das Konzept sozialer Anomie als Analyseinstrument”. En: Waldmann, Peter (ed.): Diktatur, Demokratisierung und soziale Anomie. Schriften der Philosophischen Fakultäten der Universität Augsburg, Nr. 70. München: Ernst Vögel, pp. 37-59.

Žižek, Slavoj (1992): El sublime objeto de la ideología. México, D.F.: Siglo XXI.

- (2001): El espinoso sujeto. Buenos Aires: Paidós. 
